\title{
Factors Influencing Treatment Decisions among Breast Cancer Patients in the Philippine General Hospital Cancer Institute-Medical Oncology Outpatient Clinic
}

\author{
Bobby G. de Guzman ${ }^{1} \quad$ Norman F. Cabaya ${ }^{1} \quad$ Frederic Ivan L. Ting ${ }^{1} \quad$ Jennifer Sandoval-Tan ${ }^{1}$ \\ ${ }^{1}$ Department of Medicine, Division of Medical Oncology, \\ University of the Philippines-Philippine General Hospital, \\ Taft Avenue, Manila, Philippines \\ Address for correspondence Frederic Ivan L. Ting, MD, Department \\ of Medicine, Division of Medical Oncology, University of the \\ Philippines-Philippine General Hospital, Taft Avenue, Manila 1000, \\ Philippines (e-mail: fredtingmd@gmail.com).
}

\begin{abstract}
Keywords

- breast cancer

- treatment decisions

- factors

Introduction Breast cancer is a chronic disease and its treatment decisions exist over a relatively long time period. This study was done to identify factors influencing treatment decisions among breast cancer patients in the Philippine General Hospital Cancer Institute-Medical Oncology Outpatient Clinic.

Materials and Methods This was a cross-sectional study that made use of a questionnaire and structured interview. Descriptive statistics were utilized in the analysis of the data. This allowed identification of patient demographics, economic profile, cancer profile, sources of financial or medical assistance, and summary of patient's responses to identify the factors influencing treatment decisions among breast cancer patients.

Results A total of 272 participants were included. This study identified the following factors as having influence on treatment decisions: high level of satisfaction to the consultation with their attending physician, caring and sincere communication about prognosis and likelihood of benefit from treatment, family as person of influence, the patient's collaborative role in the decision making process, the desire of cure, and trust with their doctors.

Conclusion Health practices and treatment decisions among Filipino breast cancer patients are widely affected by an interplay of the following factors: family, community, doctor's recommendations, patient's satisfaction and participation in the decision-making, health care access, and adverse treatments.
\end{abstract}

\section{Introduction}

Breast cancer is the most frequently diagnosed cancer worldwide, with nearly two million new cases diagnosed in 2018. It is the leading cause of cancer-related death in women and represents $\sim 12 \%$ of all new cancer cases and $25 \%$ of all cancers in women. ${ }^{1}$

In the Philippines, breast cancer is the most common cancer among women and its incidence starts to rise sharply at the age 30 with an average annual increase of $1.2 \%{ }^{2}$

Breast cancer is a chronic disease and its treatment decisions exist over a relatively long time period. Upon diagnosis, the decision process differs from person to person. The patients then meet choices about surgical treatment and the need for adjuvant treatment, taking into consideration surgery, chemotherapy, and radiation therapy to name a few. However, these decisions are not clear cut and mandates a continuous and thorough discussion of treatment options between the patient and the physician. Despite efforts around the world toward increased patient participation in their health care management, most people still do not use these ideals into practice. ${ }^{3}$

Discussion regarding the treatment options occurs in different ways. More often than not, the Filipino patient has a passive role in choosing treatment options and leaves to his or

\section{License terms}

()(1) $\ominus \circledast$ 
her physician what is the best to be done. However, majority of the Filipino physicians actively involve the patient in the decision-making process especially in choosing treatment options. $^{3}$

It is a fact that there are many factors affecting the treatment decision process. ${ }^{3}$ These factors include patient-centered characteristics including age and education of the patient, disease-centered prognostic characteristics such as the stage of cancer and patient's performance status (PS), and communication factors such as the enthusiasm of the patient to interact with his/her physician regarding disease information and plan of treatment.

This study aimed to identify factors influencing treatment decisions among breast cancer patients in the Philippine General Hospital Cancer Institute-Medical Oncology Outpatient Clinic. Furthermore, factors that influence patients' acceptance or refusal of the physicians' treatment recommendations and patient perceptions in the decision-making process will be determined

\section{Materials and Methods}

The study used a questionnaire and structured interview adapted from a study done by Grunfeld et al. ${ }^{4}$ After informed consent was obtained, participants were asked to complete the structured questionnaire and interview. The questionnaire was divided into three (3) parts: (1) Demographic characteristics and economic profile including age, sex, marital status, employment status, educational attainment, current place of residence or address and monthly family/household income; (2) patient's cancer profile including the first noted signs/symptoms of breast disease, date the signs/symptoms of breast disease were noted, date of first consult with the physician, breast cancer stage, hormonal status, PS and recommended cancer treatment/s by the physician (curative or palliative chemotherapy, hormonal therapy, radiotherapy, surgery, supportive care or multimodality treatment); (3) Sources of financial or medical assistance obtained from patients' records by the researchers.

The structured interview had three parts: (1) recall of key clinical decision making consultations, (2) perceptions of information disclosure, (3) perceptions of the clinical decision making process and a feedback portion that included proposals or suggestions to enhance the decision-making experiences of breast cancer patients. Ethical approval was obtained from the hospital ethics review committee.

\section{Statistical Analysis}

Descriptive statistics were utilized in the analysis of the data acquired from the recruited participants. This allowed identification of patient demographics, economic profile, cancer profile, sources of financial or medical assistance, and summary of patients' responses to identify the factors influencing treatment decisions among breast cancer patients.

\section{Results}

\section{Demographic and Economic Profile of Study Participants}

A total of 272 participants consented and were included in the analysis of the study. The mean age was 52 . All of the participants were females and $72.43 \%$ were married. Almost half of the study participants had a college degree and $43.38 \%$ lived in the CALABARZON region. Other patient characteristics are summarized in - Table $\mathbf{1}$.

Table 1 Demographic and economic profile of study participants

\begin{tabular}{|l|l|}
\hline Characteristics & $\begin{array}{l}\text { Frequency (\%) } \\
(\boldsymbol{n}=\mathbf{2 7 2})\end{array}$ \\
\hline Age, years & \\
\hline $20-29$ & $4(1.47 \%)$ \\
\hline $30-39$ & $29(10.66 \%)$ \\
\hline $40-49$ & $77(28.31 \%)$ \\
\hline $50-59$ & $103(37.87 \%)$ \\
\hline $60-69$ & $51(18.75 \%)$ \\
\hline 70 years old and above & $8(2.94 \%)$ \\
\hline Gender & \\
\hline Female & $272(100.00 \%)$ \\
\hline Male & $0(0.00 \%)$ \\
\hline Marital status & \\
\hline Single & $60(22.06 \%)$ \\
\hline Married & $197(72.43 \%)$ \\
\hline Separated & $0(0.00 \%)$ \\
\hline Live-in & $0(0.00 \%)$ \\
\hline Widow/widower & $15(5.51 \%)$ \\
\hline Educational attainment & \\
\hline Postgraduate degree & $3(1.10 \%)$ \\
\hline College degree & $129(47.43 \%)$ \\
\hline High school degree & $102(37.50 \%)$ \\
\hline Elementary degree & $31(11.40 \%)$ \\
\hline Technical/vocational & $7(2.57 \%)$ \\
\hline Current place of residence & \\
\hline National Capital Region & $104(38.24 \%)$ \\
\hline Region IV-A & $118(43.38 \%)$ \\
\hline Other regions & $50(18.38 \%)$ \\
\hline Monthly household income & \\
\hline Less than Php 3,000 & $4(1.47 \%)$ \\
\hline Php 3,000-Php 4,999 & $17(6.25 \%)$ \\
\hline Php 5,000-Php 7,999 & $60(22.06 \%)$ \\
\hline Php 8,000-Php 19,999 & $129(47.43 \%)$ \\
\hline Php 20,000 and above & $62(22.79 \%)$ \\
\hline
\end{tabular}




\section{Clinical Profile of Study Participants}

The cancer clinical profile of the study participants were examined and their notable experiences on the onset of the disease were summarized into frequency distributions (-Table 2 ).

As observed, $95 \%$ of the study participants identified palpable breast mass as the initial sign they had on the onset of the breast disease. In terms of consulting their cases to specialist, $39.71 \%$ immediately consulted a health specialist less than a month after they noted the initial signs of disease. Furthermore, the median interval from the date of first noted sign/symptom to first consultation was 1 month; that is, half of the patients tend to consult/report their condition 1 month or less after they experienced the first sign/symptom.

In terms of cancer stage during the time of this study, 51 and $7 \%$ of the study participants have stage III and stage IV disease, respectively. Around two-thirds (65\%) of the participants have positive hormonal receptor status and a little more than half of the participants (51\%) have positive Her2Neu status. In terms of PS, there is only one patient who

Table 2 Clinical profile of study participants

\begin{tabular}{|c|c|}
\hline Variable & $\begin{array}{l}\text { Frequency (\%) } \\
(n=272)\end{array}$ \\
\hline \multicolumn{2}{|l|}{ First noted signs/symptoms of breast disease } \\
\hline Palpable breast mass & $259(95.22 \%)$ \\
\hline Bloody breast discharges & $8(2.94 \%)$ \\
\hline Breast dumpling & $1(0.37 \%)$ \\
\hline Breast pain & $4(1.47 \%)$ \\
\hline \multicolumn{2}{|l|}{ Oldest and latest case } \\
\hline Oldest case: Date of 1st noted signs/symptoms of breast disease & June 1997 \\
\hline Oldest case: Date of 1st consult with physician of breast disease & June 1997 \\
\hline Latest case: Date of 1st noted signs/symptoms of breast disease & December 2018 \\
\hline Latest case: Date of 1st consult with physician of breast disease & December 2018 \\
\hline \multicolumn{2}{|l|}{ Interval from date of first noted signs/symptoms to first consult } \\
\hline 0 mo: minimum interval & $108(39.71 \%)$ \\
\hline 1 mo: median interval & $40(14.71 \%)$ \\
\hline $2 \mathrm{mo}$ & $23(8.46 \%)$ \\
\hline $3 \mathrm{mo}$ & $13(4.78 \%)$ \\
\hline $4 \mathrm{mo}$ & $11(4.04 \%)$ \\
\hline $5 \mathrm{mo}$ & $9(3.31 \%)$ \\
\hline $6 \mathrm{mo}$ & $3(1.10 \%)$ \\
\hline $7 \mathrm{mo}$ & $6(2.21 \%)$ \\
\hline $8 \mathrm{mo}$ & $2(0.74 \%)$ \\
\hline $9 \mathrm{mo}$ & $5(1.84 \%)$ \\
\hline $10 \mathrm{mo}$ & $3(1.10 \%)$ \\
\hline $12 \mathrm{mo}$ & 20 (7.35\%) \\
\hline $14 \mathrm{mo}$ & $3(1.10 \%)$ \\
\hline $18 \mathrm{mo}$ & $1(0.37 \%)$ \\
\hline $24 \mathrm{mo}$ & $12(4.41 \%)$ \\
\hline $28 \mathrm{mo}$ & $1(0.37 \%)$ \\
\hline $31 \mathrm{mo}$ & $1(0.37 \%)$ \\
\hline $33 \mathrm{mo}$ & $3(1.10 \%)$ \\
\hline $36 \mathrm{mo}$ & $1(0.37 \%)$ \\
\hline 39 mo & $2(0.74 \%)$ \\
\hline $48 \mathrm{mo}$ & $2(0.74 \%)$ \\
\hline $60 \mathrm{mo}$ & $2(0.74 \%)$ \\
\hline 90 mo: maximum interval & $1(0.37 \%)$ \\
\hline
\end{tabular}


Table 2 (continued)

\begin{tabular}{|c|c|}
\hline Variable & $\begin{array}{l}\text { Frequency (\%) } \\
(n=272)\end{array}$ \\
\hline \multicolumn{2}{|l|}{ Breast cancer stage } \\
\hline Stage I & $10(3.68 \%)$ \\
\hline Stage II & 104 (38.24\%) \\
\hline Stage III & 139 (51.10\%) \\
\hline Stage IV & $19(6.99 \%)$ \\
\hline \multicolumn{2}{|l|}{ Hormonal receptor status } \\
\hline Positive & 177 (65.07\%) \\
\hline Negative & 95 (34.93\%) \\
\hline \multicolumn{2}{|l|}{ Her2Neu status } \\
\hline Positive & $140(51.47 \%)$ \\
\hline Negative & $132(48.53 \%)$ \\
\hline \multicolumn{2}{|l|}{ Performance status (PS) } \\
\hline PS 0 & 271 (99.63\%) \\
\hline PS 1 & $1(0.37 \%)$ \\
\hline \multicolumn{2}{|c|}{ Recommended treatment by physician ${ }^{a}$} \\
\hline Surgery & $256(94.12 \%)$ \\
\hline Curative chemotherapy & $252(92.65 \%)$ \\
\hline Radiotherapy & $156(57.35 \%)$ \\
\hline Hormonal therapy & $110(40.44 \%)$ \\
\hline Palliative chemotherapy & $19(6.99 \%)$ \\
\hline Supportive care & $16(5.88 \%)$ \\
\hline
\end{tabular}

aMultiple response item (frequencies do not sum up to $272,100 \%$ ).

had an Eastern Clinical Oncology Group PS of 1, while the rest had $\mathrm{PS}=0$.

The participants were also asked what treatment procedures their physicians recommended to them during their first consultation. As observed, curative surgery and adjuvant chemotherapy were recommended for $94 \%$ and $93 \%$ of the patients, respectively. On the other hand, palliative chemotherapy and best supportive care were the least recommended treatments $(<10 \%)$.

\section{Sources of Financial/Medical Assistance}

Almost all study participants (267, 98\%) of the study participants are assisted financially by the Philippine Health Insurance Company: the country's national insurance agency (-Table 3 ). Furthermore, around half of the study participants $(52 \%)$ were identified to be assisted by the Department of Health Breast Cancer Medicines Access Program. Unfortunately, there were two patients having no known source of medical/financial assistance.

\section{Recall of Clinical Decision-Making Consultation}

This section contained three open-ended questions centering on the main topics discussed during the initial consultation that included treatment plans, treatment benefit perceptions, and adverse effects of treatment. Three fixed-choice questions that included adverse treatment concerns, doctors'
Table 3 Sources of financial/medical assistance

\begin{tabular}{|l|l|}
\hline Variable & $\begin{array}{l}\text { Frequency (\%) } \\
(\boldsymbol{n}=272)\end{array}$ \\
\hline Source of financial/medical assistance ${ }^{\mathrm{a}}$ & \\
\hline Philhealth & $267(98.16 \%)$ \\
\hline DOH-BCMAP & $141(51.84 \%)$ \\
\hline None & $2(0.74 \%)$ \\
\hline Others & $4(1.47 \%)$ \\
\hline
\end{tabular}

Abbreviation: DOH-BCMAP, Department of Health Breast Cancer Medicines Access Program.

aMultiple response item (frequencies do not sum up to 272, 100\%).

approach in the consultation, and overall levels of satisfaction with the initial consultation and one question that is answerable by yes or no regarding the over-all recall of consultation. The responses were summarized in - Table 4.

The results show that among the 272 study participants, there is only one patient who was unable to recall any discussions about breast cancer management during the initial consultation. Among several aspects of cancer management being discussed during the initial consultation, chemotherapy plans were the most recalled topic. Furthermore, the second most recalled topic were the surgical plans-as recalled by $93 \%$ of the study participants. On the other hand, 
Table 4 Recall of clinical decision-making consultation

\begin{tabular}{|c|c|}
\hline Variable & $\begin{array}{l}\text { Frequency }(\%) \\
(n=272)\end{array}$ \\
\hline $\begin{array}{l}\text { Did the patient recall the discussions about your breast cancer management during the initial } \\
\text { consultation? }\end{array}$ & Yes, 271 (99.63\%) \\
\hline \multicolumn{2}{|l|}{$\begin{array}{l}\text { Topics/aspects of cancer management being discussed during initial consultation, and still } \\
\text { being recalled at the time of interview }{ }^{\mathrm{a}}\end{array}$} \\
\hline Chemo plans & $270(99.26 \%)$ \\
\hline Surgical plans & $254(93.38 \%)$ \\
\hline Radiotherapy plans & $121(44.49 \%)$ \\
\hline Hormonal therapy plans & $53(19.49 \%)$ \\
\hline Other tests/procedures/workup & $2(0.74 \%)$ \\
\hline \multicolumn{2}{|l|}{ The benefits of the treatment, as recalled } \\
\hline To kill or control cancer cells & $208(76.47 \%)$ \\
\hline Reducing signs/symptoms (decrease breast mass size) & $22(8.09 \%)$ \\
\hline To prolong life & $42(15.44 \%)$ \\
\hline \multicolumn{2}{|l|}{ Adverse events of the treatment, as recalled ${ }^{\mathrm{a}}$} \\
\hline Hair loss & $268(98.53 \%)$ \\
\hline Body weakness & $156(57.35 \%)$ \\
\hline Nausea/vomiting & $151(55.51 \%)$ \\
\hline Loss of appetite & 48 (17.65\%) \\
\hline Dizziness & $43(15.81 \%)$ \\
\hline Mucositis & $8(2.94 \%)$ \\
\hline Discoloration of hands/feet & $7(2.57 \%)$ \\
\hline Fatigue & $5(1.84 \%)$ \\
\hline Depression & $5(1.84 \%)$ \\
\hline Insomnia & $2(0.74 \%)$ \\
\hline \multicolumn{2}{|l|}{ Overall recall of concern about adverse effects of treatment } \\
\hline Not at all concerned & $20(7.35 \%)$ \\
\hline Slightly concerned & $30(11.03 \%)$ \\
\hline Somewhat concerned & $61(22.43 \%)$ \\
\hline Moderately concerned & $70(25.74 \%)$ \\
\hline Extremely concerned & $91(33.46 \%)$ \\
\hline \multicolumn{2}{|l|}{ Mean score = 2.669 (moderately concerned) } \\
\hline \multicolumn{2}{|l|}{ Overall recall of doctor's manner during the initial consultation } \\
\hline Not at all caring & $0(0.00 \%)$ \\
\hline Slightly caring & $0(0.00 \%)$ \\
\hline Somewhat caring & $5(1.84 \%)$ \\
\hline Moderately caring & $45(16.54 \%)$ \\
\hline Extremely caring & $222(81.62 \%)$ \\
\hline \multicolumn{2}{|l|}{ Mean score $=3.798$ (extremely caring) } \\
\hline Not at all satisfied & $0(0.00 \%)$ \\
\hline Slightly satisfied & $3(1.10 \%)$ \\
\hline Unsure & $0(0.00 \%)$ \\
\hline Very satisfied & $52(19.12 \%)$ \\
\hline Extremely satisfied & $217(79.78 \%)$ \\
\hline Mean score $=3.776$ (extremely satisfied) & \\
\hline
\end{tabular}

aMultiple response item (frequencies do not sum up to $272,100 \%$ ). 
only $44 \%$ of the patients remembered about radiotherapy plans, while only $19 \%$ recalled hormonal therapy plans.

In terms of the benefits of the cancer treatments, the most recalled was "to kill or control cancer cells," as remembered by $76 \%$ of the study participants. For adverse events, it is observed that 268 patients (99\%) recalled hair loss. Also, more than half of the patients recalled body weakness (57\%) and nausea/ vomiting (56\%) as adverse events of cancer treatments.

Overall, it was observed that the study participants were moderately concerned about adverse effects of the treatments. Also, one-third (33\%) of the participants were extremely concerned with these adverse events, while there were only $7 \%$ who were not concerned at all.

In terms of physicians' demeanor, the results show that the study participants perceived the doctors to be extremely caring. As noted, four out of five patients (82\%) agreed that the doctors were extremely caring and remarkably, there were no study participant that described their doctors as slightly or not caring at all.

Lastly, it can be observed that in general the study participants were extremely satisfied with their initial consultation with their attending physician. Specifically, four out of five patients (80\%) were extremely satisfied.

\section{Patients' Perceptions of Information Disclosure}

It was observed that almost all study participants (254 out of $272,93 \%$ ) perceived that their doctors were giving information about treatment and care just at the right pace (-Table 5). Likewise, 252 out of 272 (93\%) perceived that their doctors were giving them the right amount of information. Interestingly, it was noted that all study participants felt that they had enough time to ask questions or clarifications about their treatment to their physicians. Likewise, all of them understood what their physicians were explaining to them.

Overall, it can be concluded that the study participants were extremely satisfied with the information their physicians provided to them. Specifically, three out of four patients were extremely satisfied, while there were only four patients who were slightly or not satisfied at all.

\section{Patients' Perceptions of the Clinical Decision-Making Process}

All study participants agreed that their doctors directly recommended the approach to the treatment and care. Among the 272 study participants, $74 \%$ absolutely agreed with their doctors' recommendation, while there were three patients who absolutely disagreed ( - Table $\mathbf{6}$ ).

Table 5 Patients' perceptions of information disclosure

\begin{tabular}{|l|l|}
\hline Variable & $\begin{array}{l}\text { Frequency (\%) } \\
(\boldsymbol{n}=\mathbf{2 7 2})\end{array}$ \\
\hline Pace of doctor giving information about treatment and care & \\
\hline Slightly too slow & $1(0.37 \%)$ \\
\hline Too slow & $0(0.00 \%)$ \\
\hline Just at the right pace & $254(93.38 \%)$ \\
\hline Slightly too quick & $16(5.88 \%)$ \\
\hline Too quick & $1(0.37 \%)$ \\
\hline Mean score $=2.059$ (Just at the right pace) & \\
\hline Amount of information given by the doctor & \\
\hline Slightly too little information & $0(0.00 \%)$ \\
\hline Too little information & $1(0.37 \%)$ \\
\hline Right amount of information & $252(92.65 \%)$ \\
\hline Slightly too much information & $15(5.51 \%)$ \\
\hline Too much information & $4(1.47 \%)$ \\
\hline Mean score = 2.081 (right amount of information) & \\
\hline Did the patient feel that he/she have enough time to ask questions? & Yes \\
\hline Did the patient ask questions? & $272(100.00 \%)$ \\
\hline Did the patient understand everything that the doctor told to him/her? & Yes \\
& $272(100.00 \%)$ \\
\hline Level of satisfaction with the given information & Yes \\
\hline Not all satisfied & $272(100.00 \%)$ \\
\hline Slightly satisfied & \\
\hline Unsure & $2(0.74 \%)$ \\
\hline Very satisfied & $2(0.74 \%)$ \\
\hline Extremely satisfied & $0(0.00 \%)$ \\
\hline Mean score = 3.721 (Very Satisfied) & $62(22.79 \%)$ \\
\hline & $206(75.74 \%)$ \\
\hline
\end{tabular}


Generally, the study participants were too quick to reach their decisions about the treatment/care. Specifically, around two-thirds of the patients (64\%) were slightly too quick in making their decisions, while less than $10 \%$ of the patients took a too long time before coming up with their decisions.

In terms of satisfaction on how the treatment and care plan have been decided, the study participants were extremely satisfied. Specifically, $78 \%$ of the study participants were extremely satisfied, while there were three patients who were slightly satisfied with their decisions.

\section{Persons and Factors Influencing Patients' Decision-Making}

The participants were asked to name one person whom they deemed to be the most influential to their decision-making. Results showed that their family was the most influential (73\%), while their oncologists were most influential to $15 \%$ of the study participants ( - Table 7 ).

Among several factors of influence in accepting cancer treatment decisions, it can be concluded that the "desire of cure" is deemed the most influential, as perceived by $86 \%$ of the study participants. On the other hand, "possibility of controlling tumor" is the least influential as only three participants said that this was the factor of influence in decision-making.

\section{Patients' Perceptions of Their Participation in the Decision-Making Process}

Two-hundred sixty-six study participants thought to have shared their treatment decisions with their doctors in a collaborative role. Two patients were noted to have made the final decision by themselves even if it was against the doctors' recommendations. Interestingly, one patient claimed that she asked her doctor to make the final treatment decision for her after considering her view (-Table 8).

\section{Patients' Proposals/Suggestions to Enhance the} Decision-Making Experiences of Breast Cancer Patients To enhance the decision-making experiences of breast cancer patients, almost half of the participants recommended that patients should trust their doctors and listen to their advice (-Table 9). Furthermore, 40\% proposed that they should consult a doctor immediately once with signs/ symptoms of disease. About 23\% suggested that the patients should have a positive outlook in life and should not lose hope. Also $13 \%$ of the participants suggested praying.

Table 6 Patients' perceptions of the clinical decision-making process

\begin{tabular}{|c|c|}
\hline Variable & $\begin{array}{l}\text { Frequency }(\%) \\
(n=272)\end{array}$ \\
\hline Did the doctor directly recommend the approach to the treatment/care? & $272(100.00 \%)$ \\
\hline \multicolumn{2}{|l|}{ Level of agreement with the doctor about the treatment and care } \\
\hline Absolutely disagree & $3(1.10 \%)$ \\
\hline Slightly disagree & $0(0.00 \%)$ \\
\hline Cannot estimate & $3(1.10 \%)$ \\
\hline Fairly agree & $65(23.90 \%)$ \\
\hline Absolutely agree & $201(73.90 \%)$ \\
\hline \multicolumn{2}{|l|}{ Mean score $=3.695$ (absolutely agree) } \\
\hline \multicolumn{2}{|l|}{ Perception on the length of time taken to reach the decision } \\
\hline Slightly too quick & $175(64.34 \%)$ \\
\hline Too quick & $7(2.57 \%)$ \\
\hline Right amount of time & $63(23.16 \%)$ \\
\hline Slightly too long & $19(6.99 \%)$ \\
\hline Too long & $8(2.94 \%)$ \\
\hline \multicolumn{2}{|l|}{ Mean score $=0.816$ (too quick) } \\
\hline \multicolumn{2}{|l|}{ Level of satisfaction on how the treatment and care plan has been decided } \\
\hline Not at all satisfied & $0(0.00 \%)$ \\
\hline Slightly satisfied & $3(1.10 \%)$ \\
\hline Unsure & $0(0.00 \%)$ \\
\hline Very satisfied & $57(20.96 \%)$ \\
\hline Extremely satisfied & $212(77.94 \%)$ \\
\hline Mean score $=3.757$ (very satisfied) & \\
\hline
\end{tabular}


Table 7 Persons and factors influencing patients' decision-making

\begin{tabular}{|l|l|}
\hline Variable & $\begin{array}{l}\text { Frequency (\%) } \\
(\boldsymbol{n}=\mathbf{2 7 2})\end{array}$ \\
\hline Person of influence in your treatment decision-making & \\
\hline Oncologist & $41(15.07 \%)$ \\
\hline Family & $199(73.16 \%)$ \\
\hline Partner & $17(6.25 \%)$ \\
\hline Nurse & $0(0.00 \%)$ \\
\hline General practitioner & $2(0.74 \%)$ \\
\hline Self & $13(4.78 \%)$ \\
\hline Factors of influence in accepting cancer treatment decisions & \\
\hline Desire of cure & $235(86.40 \%)$ \\
\hline Possibility of controlling tumor & $3(1.10 \%)$ \\
\hline Maintaining sense of hope & $7(2.57 \%)$ \\
\hline Prolong life & $27(9.93 \%)$ \\
\hline Factors of influence in refusing cancer treatment decisions & No factor (all patients agreed on treatments advised) \\
\hline
\end{tabular}

Table 8 Patients' perceptions of their participation in the decision-making process

\begin{tabular}{|l|l|}
\hline Variable & $\begin{array}{l}\text { Frequency (\%) } \\
(\boldsymbol{n}=272)\end{array}$ \\
\hline Patient's perceptions of their participation in the decision-making & \\
\hline I made the final decision (active role) & $2(0.74 \%)$ \\
\hline I made the final decision after seriously considering my doctor's view (active role) & $3(1.10 \%)$ \\
\hline My doctor and I shared responsibility (collaborative role) & $266(97.79 \%)$ \\
\hline My doctor made the final decision after seriously considering my view (passive role) & $1(0.37 \%)$ \\
\hline I left all the decisions to my doctor (passive role) & $0(0.00 \%)$ \\
\hline
\end{tabular}

Table 9 Proposals or suggestions to enhance the decision-making experiences of breast cancer patients

\begin{tabular}{|l|l|}
\hline Variable & $\begin{array}{l}\text { Frequency (\%) } \\
(\boldsymbol{n}=\mathbf{2 7 2})\end{array}$ \\
\hline Suggestions to enhance the decision-making experiences of breast cancer patientsa & \\
\hline Trust the doctor and listen to their advice & $135(49.63 \%)$ \\
\hline Consult a doctor immediately once with signs/symptoms of disease & $110(40.44 \%)$ \\
\hline Have a positive outlook in life/don't lose hope & $62(22.79 \%)$ \\
\hline Prayers & $34(12.50 \%)$ \\
\hline
\end{tabular}

aMultiple response item (frequencies do not sum up to $272,100 \%$ ).

\section{Discussion}

Breast cancer is a chronic disease and its treatment decisions exist over a relatively long time period. Upon diagnosis, the decision process differs from person to person. The patients then meet choices about surgical treatment and the need for adjuvant treatment such as chemotherapy and radiation therapy. However, these decisions are not clear cut and they require a thorough discussion between the patient and the physician.

This study analyzed patients' responses of the discussion of treatment modalities for breast cancer management including curative and palliative chemotherapy, surgery, radiation therapy, hormonal therapy, and best supportive care. In this study, almost $90 \%$ of participants have early stage breast cancer and a good PS, hence aiming for the possibility of cure. Almost all of the patients in this study had medical assistance from the national government health insurance; hence, cancer treatments are financially assisted. However, there were limitations with the use of biologic or targeted agents since they are quite expensive and the budget for this is not fully covered by the government.

High-level satisfaction of the patient correlates well in treatment decisions. In this study, the participants were extremely satisfied with their initial consultation with their attending physicians and the doctors' manner during initial consultation mattered as well. Caring and sincere 
communication about prognosis and likelihood of benefit from treatment are well documented in this study and further enhance the decision making of breast cancer patients.

Consistent with other studies, ${ }^{5-7}$ the most influential factor among breast cancer patients in this study is the "desire of cure." With the advancement of medicine in treating breast cancer, there are already a lot of treatment paradigms especially in managing early breast cancer patients. Recently, the involvement of the collaborative role of the patient in decision making has evolved and empowered the patients to work hand in hand with their doctors regarding treatment. The patients nowadays are participative in the management of their diseases. As observed in our study, almost $97 \%$ of the study participants are on collaborative role with their physician in the decision-making process as they perceived their doctors and themselves shared responsibilities in choosing what treatment should be implemented.

Maintaining a sense of hope, desire for cure, and prolonging life are highlighted in this study as key motives for accepting cancer treatment decisions among Filipino breast cancer patients. These three key motivators are central to patient well-being at all stages of the cancer journey for Filipino breast cancer patients.

\section{Conclusion}

Health practices and treatment decisions among Filipino breast cancer patients are widely affected by an interplay of the following factors: family, community, doctor's recommendations, patient's satisfaction and participation in the decision-making, health care access, and adverse treatments to name a few.

This study identified high level of satisfaction with consultation to their attending physician, caring and sincere communication about prognosis and likelihood of benefit from treatment, family as person of influence, patient's collaborative role in the decision-making process, desire of cure and trust with their doctors as factors of influence in accepting cancer treatment decisions. On the other hand, no participant in this study refused to accept cancer treatment decisions.

The study participants recommended that patients like them should trust their doctors and listen to their advice, should consult a doctor immediately once with signs/ symptoms of disease, should have a positive outlook in life, and should pray to enhance the decision-making experiences of Filipino breast cancer patients. Further studies are recommended and may be directed toward more improvement and follow-up care of breast cancer patients in a tertiary outpatient clinic.

\section{Conflict of Interest}

None declared.

\section{References}

1 Website/World Cancer Research Fund International. Breast Cancer Statistics. 2018. Available from https://www.wcrf.org/ dietandcancer/cancer-trends/breast-cancer-statistics

2 Laudico AV, Mirasol-Lumague MR, Medina V, et al. Philippine Cancer Facts and Estimates; 2015:20. Available at: http://www. philcancer.org.ph/wp-content/uploads/2017/07/2015-PCSCa-Facts-Estimates_CAN090516.pdf. Accessed March 12, 2020

3 Sattar S, Alibhai SMH, Fitch M, Krzyzanowska M, Leighl N, Puts MTE. Chemotherapy and radiation treatment decision-making experiences of older adults with cancer: a qualitative study. J Geriatr Oncol 2018;9(1):47-52

4 Grunfeld EA, Maher EJ, Browne S, et al. Advanced breast cancer patients' perceptions of decision making for palliative chemotherapy. J Clin Oncol 2006;24(7):1090-1098

5 Website/GLOBOCAN Cancer Fact Sheets, Breast Cancer Estimated Incidence, Mortality and Prevalence Worldwide in 2018, World Health Organization International Agency for Research on Cancer. 2012. Available from https://www.globocan.iarc.fr/old/FactSheets/cancers/breast-new.asp

6 Siminoff LA, Fetting JH. Factors affecting treatment decisions for a life-threatening illness: the case of medical treatment of breast cancer. Soc Sci Med 1991;32(7):813-818

7 Puts MT, Tapscott B, Fitch M, et al. A systematic review of factors influencing older adults' decision to accept or decline cancer treatment. Cancer Treat Rev 2015;41(2):197-215 